\title{
Correction to: Spasmodic cough preceding CANVAS phenotype in a family with biallelic repeat expansions in RFC1
}

\author{
Maria João Malaquias ${ }^{1} \cdot$ Catarina Mendes Pinto $^{2} \cdot$ Ana Sardoeira $^{1} \cdot$ Jorge Oliveira $^{3}$ - João Parente Freixo ${ }^{3}$. \\ Ana Aires Silva ${ }^{4}$. Pedro Abreu ${ }^{4} \cdot$ Cristina Rosado Coelho $^{5} \cdot$ Joana Damásio $^{1} \cdot$ Nuno Vila-Chã $^{1} \cdot$ Marina Magalhães $^{1,6}$
}

Published online: 23 November 2020

(C) Fondazione Società Italiana di Neurologia 2020

Correction to: Neurological Sciences (2020) https://doi.org/10.1007/s10072-020-04895-4

The original article contains an error. Figure $1 b$, letter e, the presentation of the arrow was wrong. The correct Figure 1 is presented here. The original article has been corrected.
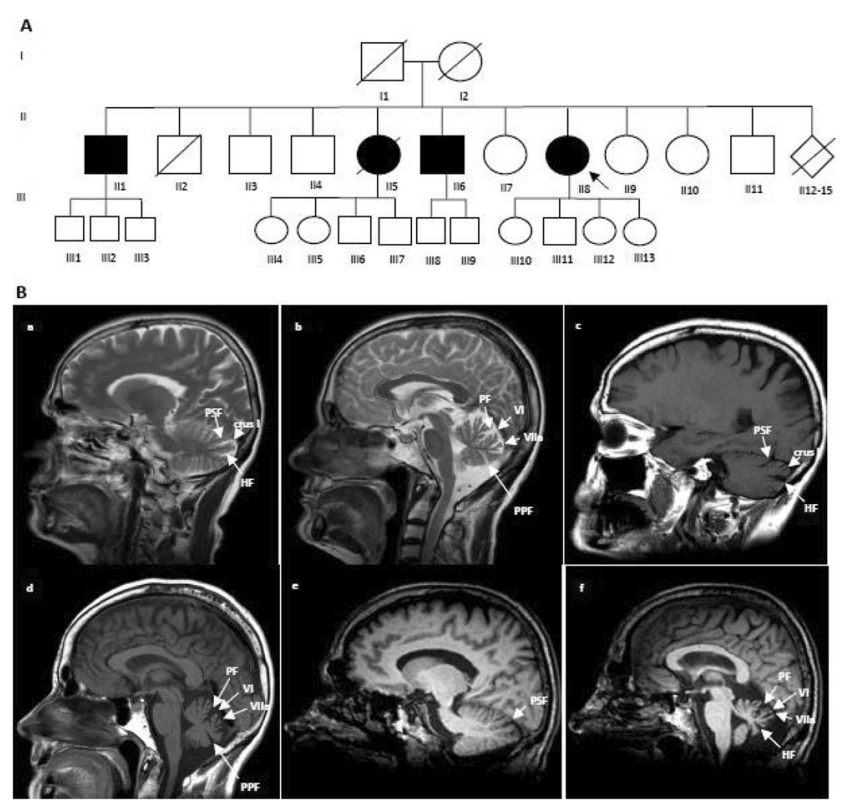

Publisher's note Springer Nature remains neutral with regard to jurisdictional claims in published maps and institutional affiliations.

Center for Predictive and Preventive Genetics (CGPP), Institute for Molecular and Cell Biology (IBMC), Instituto de Investigação e Inovação em Saúde (i3S), Universidade do Porto, Porto, Portugal

4 Neurology Department, Centro Hospitalar Universitário de São João, Porto, Portugal

5 Neurology Department, Centro Hospitalar de Setúbal, Lisbon, Portugal

6 Neurology Department, Hospital Padre Américo, Centro Hospitalar do Tâmega e Sousa, Penafiel, Porto, Portugal 